\title{
SELF-EMPLOYMENT IN JOINERY: AN OCCUPATIONAL RISK FACOR?
}

\section{FRANCOIS-XAVIER LESAGE, JULIE SALLES, and FREDERIC DESCHAMPS}

University Hospital of Reims, Reims, France

Department of Occupational Diseases

\begin{abstract}
Objectives: Only a few studies have analyzed the health of self-employed workers. This cross-sectional study is the first to compare health status among craftsmen joiners and paid joiners. Material and Methods: Clinical and paraclinical data for self-employed craftsmen and employees were collected by occupational health doctors according to a standardized protocol and compared. Health data and professional status relationships were analyzed by logistic regression. Results: A total of 171 craftsmen and 196 paid workers were included. Craftsmen had more dermatologic pathologies (odds ratio $(\mathrm{OR})=2.67, \mathrm{p}<0.05)$, ear/nose/throat symptoms $(\mathrm{OR}=3.38, \mathrm{p}<0.001)$, pulmonary symptoms $(\mathrm{OR}=2.46, \mathrm{p}<0.05)$, musculoskeletal symptoms $(\mathrm{OR}=3.09, \mathrm{p}<0.001)$, and abnormal audiogram $(\mathrm{OR}=3.50, \mathrm{p}<0.001)$. The $\mathrm{FEV}_{1}$ was significantly lower among craftsmen $(\mathrm{p}<0.01)$, independently of tobacco smoke exposure. Conclusions: This survey highlights a high morbidity rate among self-employed craftsmen, suggesting that among woodworkers, professional status can be a risk factor for health. The preventive medical system for craftsmen has to be rethought to guarantee better safety for this population.
\end{abstract}

Key words:

Risk factor, Craftsmen, Self-employed workers, Woodworking, Joiners, Occupational medicine

\section{INTRODUCTION}

Craftsmen represent a significant part (10\%) of the working population in France, where self-employed workers, including craftsmen, are covered by a specific insurance fund. They do not, however, have a system of preventive medicine or occupational health services. Hence, data describing their relative health status are limited. A few international studies have analyzed the cardiovascular risk among self-employed workers [1,2], finding a lower risk compared with staff workers. A US group evaluated all-cause mortality and identified a higher risk of death among all self-employed workers [3], and a French study found some associations between specific diseases and certain occupations among the self-employed [4].
Moroccan [5] and French surveys [6] assessing the occupational health status among only craftsmen and tradespeople revealed a high prevalence of different pathologies. Indeed, the Moroccan study, based on a population of 449 self-employed workers, reported a high prevalence of musculoskeletal diseases $(67.6 \%)$ and of oral (58.2\%) and ophthalmic (46.9\%) diseases, among others. In the French survey, based on a population of 139 people, the authors reported a general morbidity rate of $59.7 \%$, among which $19.4 \%$ were work-related. Respiratory dysfunction (19.4\%), musculoskeletal and skin diseases (15.8\%), and cardiovascular problems were the most frequent overall, but musculoskeletal disorders were the most common work-related problems (5.7\%),

Received: December 2, 2013. Accepted: February 5, 2014.

Corresponding author: F.-X. Lesage, University Hospital of Reims, Department of Occupational Diseases, 48 rue de Sébastopol, 51100 Reims, France (e-mail: fxlesage@chu-reims.fr). 
followed by skin, pulmonary, neurologic, and ear/nose/ throat (ENT) troubles (3.6\%).

None of these studies, however, have compared self-employed craftsmen and staff workers in the same profession. We can hypothesize that craftsmen are in poorer health because they do not receive the same level of prevention or medical supervision as employees, and because of supplementary occupational constraints related to their professional status. Here, we focus on woodworking because it represents an important economic sector, with many workers, and is well known for exposures to many occupational hazards linked to several pathologies $[7,8]$. Thus, the aim of this study was to compare the health status of joiners craftsmen and joiners employees.

\section{MATERIAL AND METHODS}

This cross-sectional study was carried out among a population of joiners in France, from April 2007 to February 2009.

\section{Populations}

Joiners craftsmen (known as 'craftsmen') are their own employers. They have their own health insurance fund. They do not have to follow most of the hygiene and security laws. Moreover, they are not subjected to medical follow-ups by a company occupational health service. For this study, they were invited by their health insurance fund to receive a clinical examination focused on occupational hazards in the Department of Occupational Diseases of Reims University Hospital. This medical examination was offered to all active craftsmen currently working in the woodworking field in 1 region of France (Champagne Ardenne).

The health service which examined craftsmen is the department of occupational diseases of Reims University Hospital. This health service does not work for a company. This is a health service which helps other physicians (specialist, occupational physicians, GP) to determine etiological diagnosis of any potential occupational disease. They train the future occupational physicians too, and conduct research in the field of occupational health.

We compared the data for this group with that of a population of paid workers (known as 'employees') in the same profession, from the same region. The employees were recruited by occupational health physicians from woodworking factories from the same region (3 joineries, 1 plywood production plant, truckers) and were seen during a routine medical visit. Employees were examined by their occupational physicians, who work in a company occupational health service. This service has to provide a yearly medical follow-up of all the paid workers in France.

Each company has its own company-based occupational physician. The physicians who follow up workers in woodworking companies offered to paid workers a possibility to participate in this study, according to the same procedure as for craftsmen. The medical examination of employees was carried out by their regular occupational physician, at their company's occupational health service premises. Each participant was informed about the purpose of the study and agreed to participate. The qualified individuals, both women and men, had to have been exposed for at least 1 year to wood dust.

The response rate was $39 \%$ among the 715 woodworking craftsmen invited to receive the clinical examination and $100 \%$ among the employees $(\mathrm{p}<0.0001)$. There were only 2 women in the joiners craftsmen group and 15 in the joiners employees group. Hence, they were excluded from the analysis. People with related jobs (carpenter, maintenance technician in woodworking, wood cutter, etc.) were excluded too. After exclusion, 171 joiners craftsmen files and 196 employees files were analyzed.

\section{Data collection}

The consultant filled out the same 3-part questionnaire for each participant. The first part covered data on sex, 
age, job, duration of occupational exposure, and smoking. Smoking was defined as active or former smoking.

The second part concerned the medical data: the presence of functional symptoms and medical examination. The consultant's search for information included an interview and a clinical examination that covered the respiratory system (presence of dyspnea), musculoskeletal system (presence of joint pain, with location), ENT system (epistaxis, stuffy nose, or frequent rhinorrhea), and the presence of skin pathology. The occupational origin of the symptoms was not assessed. The last part of the questionnaire reported the results of the lung function testing and audiogram. The spirometry was performed with a calibrated device for each participant. The results were filled in according to age, sex, ethnicity, weight, and size of the individual. We focused on the forced vital capacity (FVC) and the forced expiratory volume in $1 \mathrm{~s}\left(\mathrm{FEV}_{1}\right)$. These endpoints were considered abnormal when their values were below $80 \%$ of the theoretical results. Abnormal spirometries were classified into 3 categories: restrictive syndrome when only forced vital capacity was under $80 \%$; obstructive syndrome when only forced expiratory volume was abnormal; and mixed syndrome when both parameters were abnormal.

The audiogram was also performed with a calibrated device in a soundproof testing room. The audiogram was analyzed by a trained physician in order to determine if it would be compatible with a noise-induced hearing loss (NIHL). Selective $4000 \mathrm{~Hz}$ hearing loss is characteristic of the onset of NIHL, defined here as a hearing loss $>30 \mathrm{~dB}$ (uni- or bilateral) at $4000 \mathrm{~Hz}$ without a loss at $8000 \mathrm{~Hz}$ [9]. The global morbidity rate was defined by the presence of at least 1 functional symptom or an abnormal spirometry or audiogram.

The approval by a medical ethics review board was not required under French research ethics legislation. The workers were informed that their medical data would be used for this study, and that they were free to refuse or withdraw at any moment.

\section{Statistical analysis}

Files with missing data were excluded. We compared the 2 populations using the student's t-test for continuous variables. The significance level was set as $\mathrm{p}<0.05$. We used the Chi square test for dichotomous categorical variables (with Yates correction if necessary or the Fisher's test). Logistic models were computed in order to provide the odds ratios between the diseases and the occupational status (craftsmen or employees). The models were adjusted for category (craftsmen or employees), age, smoking, and age at the beginning of working as a joiner. Employees were used as the reference category. A "forward-backward" selection procedure was computed for each initial model. All analyzes were performed with R software and the EpiCalc package.

\section{RESULTS}

Table 1 shows the distribution of the populations in terms of age, smoking, years of service in the joinery, and the age when they began to work as a joiner. The age of the subjects and their years of service in woodworking (as craftsmen or employees) are highly correlated $(\mathrm{r}=0.81)$.

The global morbidity rate of the 2 populations was $68.8 \%$. This rate among craftsmen was $89.3 \%$, while it was $52.9 \%$ among employees $(p<0.001)$. Table 2 shows the distribution of the different diseases locations in the 2 populations. After adjustment, the prevalence of each symptom remained statistically higher among craftsmen (Table 2).

An ethmoid adenocarcinoma was discovered in 1 craftsman. The prevalence of rachis pain (cervical, dorsal and back pain) and lower limbs pain was significantly higher among craftsmen, but there was no difference concerning the upper limbs (Table 3).

The audiogram results differed statistically between the 2 populations according to the used criteria, with 
Table 1. Demographic characteristics of craftsmen and employees

\begin{tabular}{lccc}
\hline \multicolumn{1}{c}{ Variable } & $\begin{array}{c}\text { Craftsmen } \\
(\mathrm{N}=171)\end{array}$ & $\begin{array}{c}\text { Employees } \\
(\mathrm{N}=196)\end{array}$ & $\mathrm{p}$ \\
\hline Age (years) $(\mathrm{M} \pm \mathrm{SD})$ & $47.1 \pm 8.1$ & $39.9 \pm 10.7$ & $<0.001$ \\
Years in joinery (years) $(\mathrm{M} \pm \mathrm{SD})$ & $27.1 \pm 10.9$ & $18.3 \pm 10.7$ & $<0.001$ \\
Age at the beginning as a joiner $(\mathrm{M} \pm \mathrm{SD})$ & $20.0 \pm 6.8$ & $21.6 \pm 6.4$ & $<0.050$ \\
Smoking status: smokers $(\%)$ & 28.7 & 49.5 & $<0.001$ \\
\hline
\end{tabular}

$\mathrm{M}$ - mean; SD - standard deviation.

Table 2. Distribution of diseases among craftsmen and employed male joiners

\begin{tabular}{|c|c|c|c|c|}
\hline \multirow[b]{2}{*}{ Disease } & \multirow{2}{*}{$\begin{array}{c}\text { Craftsmen } \\
(\mathrm{N}=171) \\
(\%)\end{array}$} & \multirow{2}{*}{$\begin{array}{c}\text { Employees } \\
(\mathrm{N}=196) \\
(\%)\end{array}$} & \multicolumn{2}{|c|}{ OR } \\
\hline & & & crude & adjusted $^{\mathrm{a}, \mathrm{b}}$ \\
\hline Dermatology & 14.6 & 5.1 & $3.18 * *$ & $2.67^{*}$ \\
\hline Dyspnea & 15.8 & 7.7 & $2.25^{*}$ & $2.46^{*}$ \\
\hline Musculoskeletal & 63.2 & 30.6 & $3.89 * * *$ & $3.09 * * *$ \\
\hline ENT & 45.6 & 20.9 & $3.17^{* * *}$ & $3.38 * * *$ \\
\hline Hearing loss & 74.6 & 35.4 & $5.36^{* * *}$ & $3.50 * * *$ \\
\hline Spirometry & 16.0 & 11.4 & $1.48^{\mathrm{ns}}$ & $1.16^{\mathrm{ns}}$ \\
\hline Morbidity & 89.3 & 52.9 & $7.42^{* * *}$ & $6.05^{* * *}$ \\
\hline
\end{tabular}

ENT - ear/nose/throat; OR - odds ratio.

${ }^{*} \mathrm{p}<0.05,{ }^{* *} \mathrm{p}<0.01,{ }^{* * *} \mathrm{p}<0.001$.

ns - non-significant ( $\mathrm{p}>0.05)$.

${ }^{a}$ Adjusted for age and smoking.

${ }^{\mathrm{b}}$ Employees $=$ referent categories.

Table 3. Distribution of joint pain among craftsmen and employed male joiners

\begin{tabular}{|c|c|c|c|c|}
\hline \multirow{2}{*}{$\begin{array}{c}\text { Joint pain } \\
\text { location }\end{array}$} & \multirow{2}{*}{$\begin{array}{c}\text { Craftsmen } \\
(\mathrm{N}=171) \\
(\%)\end{array}$} & \multirow{2}{*}{$\begin{array}{c}\text { Employees } \\
(\mathrm{N}=196) \\
(\%)\end{array}$} & \multicolumn{2}{|c|}{ OR } \\
\hline & & & crude & adjusted $^{\mathrm{a}}$ \\
\hline Upper limb & 34.1 & 22.4 & $1.79 * *$ & $1.41^{\mathrm{ns}}$ \\
\hline Lower limb & 29.3 & 12.1 & $3.01 * * *$ & $3.03^{* * *}$ \\
\hline Rachis & 15.4 & 4.3 & $4.08^{* * *}$ & $3.03^{* * *}$ \\
\hline
\end{tabular}

${ }^{a}$ Adjusted for age.

Other abbreviations as in Table 2.

a larger degradation in craftsmen (adjusted odd ratio $(\mathrm{ORa})=3.29, \mathrm{p}<0.001)$.

As regards the spirometry results, the mean of the percentage of the predicted ( $\%$ predicted) $\mathrm{FEV}_{1}$ was lower among craftsmen, smokers or non-smokers $(\mathrm{p}<0.01)$ (Table 4). The mean of the percentage of the predicted (\% predicted) $\mathrm{FEV}_{1}$ was lower only among smoking craftsmen $(\mathrm{p}<0.05)$. The obstructive syndrome was more 
Table 4. Spirometric parameters' values among craftsmen and employed male joiners

\begin{tabular}{lccc}
\hline \multicolumn{1}{c}{ Variable } & $\begin{array}{c}\text { Craftsmen } \\
(\mathrm{N}=171)\end{array}$ & $\begin{array}{c}\text { Employees } \\
(\mathrm{N}=196)\end{array}$ & $\mathrm{p}$ \\
\hline Predicted FEV $(\mathrm{M} \pm \mathrm{SD})$ & $95.2 \pm 14.7$ & $103.9 \pm 22.3$ & $* * *$ \\
$\quad$ smokers & $91.4 \pm 10.5$ & $102.7 \pm 22.5$ & $* *$ \\
non-smokers & $96.7 \pm 15.8$ & $105.1 \pm 22.1$ & $* *$ \\
Predicted FVC $(\mathrm{M} \pm \mathrm{SD})$ & $96.5 \pm 14.7$ & $101.1 \pm 21.1$ & $*$ \\
$\quad$ smokers & $93.7 \pm 14.5$ & $101.9 \pm 21.1$ & $\mathrm{n}$ \\
non-smokers & $97.6 \pm 16.0$ & $100.2 \pm 21.1$ & $\mathrm{~ns}$ \\
\hline
\end{tabular}

$\mathrm{FEV}_{1}$ - forced expiratory volume in $1 \mathrm{~s} ; \mathrm{FVC}$ - forced vital capacity.

Other abbreviations as in Table 2.

Table 5. Distribution of restrictive, obstructive, and mixed syndromes among craftsmen and employed male joiners, at spirometry

\begin{tabular}{lcccc}
\hline \multicolumn{1}{c}{ Variable } & $\begin{array}{c}\text { Craftsmen } \\
(\mathrm{N}=171)\end{array}$ & $\begin{array}{c}\text { Employees } \\
(\mathrm{N}=196)\end{array}$ & & \multicolumn{2}{c}{ OR } \\
\hline $\begin{array}{l}\text { Respiratory syndromes } \\
\text { (\% of prevalence })\end{array}$ & & & & adjusted $(\mathrm{p})^{\mathrm{a}, \mathrm{b}}$ \\
restrictive syndrome & 4.7 & 2.1 & $2.35^{\mathrm{ns}}$ & \\
obstructive syndrome & 5.3 & 1.6 & $3.56^{*}$ & $2.51^{\mathrm{ns}}$ \\
mixed syndrome & 5.9 & 7.8 & $0.75^{\mathrm{ns}}$ & $3.56^{\mathrm{ns}}$ \\
\hline
\end{tabular}

a Adjusted for smoking.

Other abbreviations as in Table 1 and 2.

frequent among craftsmen (crude OR $=3.32, \mathrm{p}=0.03$ ), but it was no more statistically significant after adjustment for smoking and the job $(\mathrm{ORa}=3.31, \mathrm{p}=0.06)$ (Table 5).

\section{DISCUSSION}

The findings suggest that craftsmen are less healthy than employees. The craftsmen's morbidity rate $(89.3 \%)$ was higher than that of the employees population (52.9\%) $(\mathrm{ORa}=6.05, \mathrm{p}<0.001)$. We cannot compare this rate with the findings in the literature because there are no specific data for woodworking, but our self-employed population had a very high morbidity rate compared to the Moroccan and French studies [5,6]. This very high prevalence may be explained by the used criteria.

Joint pain appears to be more frequent in craftsmen, with the knee and back pain as the predominant locations.
A Swedish survey [10] also found more knee osteoarthritis in wood workers $(\mathrm{OR}=2.02,95 \% \mathrm{CI}$ : 1.11-3.69), while the French survey [6] evaluating the health status of craftsmen among baker-pastry cooks, house painters, and hairdressers found that the first functional complaint concerned the musculoskeletal system, with a prevalence of 5.7\%. The Moroccan survey provided a similar result with a prevalence of $67.6 \%$ for the handicraft sector and $47.2 \%$ for self-employed woodworkers [5]. A larger workload, associated with time constraints, and higher stress could explain these results. Indeed, craftsmen often work alone and ensure the efficiency of their business by themselves. Moreover, they often work more hours per week.

Audiograms were abnormal among craftsmen twice as much as among employees (ORa $=3.50, \mathrm{p}<0.001)$. A Norwegian survey also found higher hearing thresh- 
olds in woodworkers (OR $=1.7,95 \%$ CI: 1.4-2.3) [11]. The greater prevalence of these hearing losses in craftsmen supports the idea of a misuse of protective equipment under an otherwise equal exposure. Two studies have affirmed that craftsmen engage in a more limited use of collective and individual technical protection [5,12].

On the other hand, spirometry results highlight that craftsmen (smokers or non-smokers) have a lower FEV $\mathrm{F}_{1}$. Moreover, we did identify more dyspnea among craftsmen in our study. However, there were no spirometric syndromes (restrictive, obstructive or mixed syndromes) after adjustments. In the literature, data are contradictory for this endpoint [8,13-17]. Some studies suggest an exposureeffect relationship between lung function alteration and wood dust [8], but others have not found this effect. The absence of statistical differences in the prevalence of obstructive and restrictive syndromes may be explained by the fact that the observed prevalence is weak. The power of this study is probably too weak to allow to highlight a statistically significant increase of lung diseases. On the contrary, there is a significant decrease of the $\mathrm{FEV}_{1}$ among craftsmen, independently of a tobacco smoke exposure. This may indicate some differences in occupational respiratory exposure. The role of the wood dust cannot be argued. The joiners may use or be exposed to numerous toxic substances while performing the different tasks. But this result highlights a lower protection level against respiratory exposures.

There are several important limitations in this study, which need to be taken into account.

The main limitation is the low response rate among craftsmen (39\%). The recruitment process may have created a selection bias; indeed, based on volunteering for craftsmen, this recruitment may have selected craftsmen with health problems. Several factors could explain why a craftsman has decided or not to come to the medical check-up proposed by their health insurance fund.
First, craftsmen needed to go to the Reims University Hospital, which is the only medical center for craftsmen. This may require a long journey for craftsmen working in the southern part of the region. They needed more than $4 \mathrm{~h}$ to do the round trip. Thus, they may have declined the invitation for this reason. Second, craftsmen did not earn money when they came for the medical examination, because they were not working. Third, such low response rate supports the hypothesis that craftsmen may have a lower level of medical care, and one reason for it is the lack of time.

Perhaps the feeling of poorer health could have led craftsmen to take the opportunity of a free medical check-over, but there are several arguments against it. A medical examination is free in France. Moreover, the proposed check-over was preventive, and craftsmen have been informed that they would not be treated for a potential disease. Consequently, a craftsman with a medical problem would probably prefer to consult a doctor in their own town than to have the preventive check-over. In addition to this, the slight decrease of spirometric parameters highlighted in this study would probably not lead to a feeling of poorer health. Therefore, this feeling was not a major factor of response to our invitation. It is likely that these were not craftsmen with health problems who came for this medical examination, but rather those who lived close to the hospital. Consequently, the perceived health probably did not induce a major systematic bias of selection. Another potential bias was an observation bias, because different occupational health physicians handled the clinical examination within the population. Moreover, the occupational physicians knew the status (craftsmen or employees) of the worker. Nevertheless, the same method of data collection was used for both populations, with professionals asking closed questions. This form of data collection guarantees a better quality and homogeneity of data, in contrast to a self-completed questionnaire or a retrospective study based on medical records. 
There are numerous differences between these 2 populations. On average, craftsmen began their self-employment careers at the age of 40, which could explain their higher mean age. Most joiners had not practised other jobs before. There are differences in job exposure, too. There is a large variety of jobs among employees: foremen, forklift operators, maintenance technicians, joiners. On the other hand, jobs are more homogeneous among craftsmen. Most of them are joiners. Hence, this study was carried out among joiners only. Occupational exposures are probably different between employees and craftsmen: rhythms of the work, loading, alternation of tasks. Some data were collected during the medical examination in this study. Unfortunately, these data were not objective enough to be interpreted. Consequently, the analysis was conducted in 2 relatively like-for-like jobs: joiner craftsmen and employees.

The selection and observational bias may not be the only bias in this study. The findings may be influenced by a healthy worker effect. Moreover, employees who developed disabling disease or symptoms related to work tended to leave their company (sometimes following a dismissal) and settle as craftsmen because they could not find a job in another field of activity. There is certainly a lack of data concerning the work history and the work conditions in this study. But these data would be partly subjective. For example, a craftsman could declare during the medical interview to work $100 \mathrm{~h}$ per week. This study design does not allow to validate such data. In the same way, a worker could declare the use of personal protective equipment, even if he usually did not use it. Craftsmen have been invited to participate in this study by their health insurance fund. It is likely that this recruitment process induced a serious bias concerning this type of subjective data on preventive measures. Consequently, we chose to collect only some more objective data from medical examination.

More details concerning job exposure would provide very interesting data. For example, wood dust is well known to cause multiple pathologies or symptoms $[7,8,10,11]$. The dermatologic, ENT, dyspnea, and rheumatologic symptoms were found with a higher prevalence among craftsmen. However, the aim of this study was not to highlight that craftsmen are more exposed to wood dust, or another occupational hazard, than employees, but to emphasize that craftsmen are less healthy than employees, i.e. that the 'craftsman status' is a risk factor in itself for health.

This study design did not allow to determine the causes. There are several hypotheses that can explain this result. The first one obviously regards the work conditions. Craftsmen have less restrictive work regulations. Consequently, prevention, hygiene and safety measures are less developed. They may have less money to invest in security equipment or handling equipment. Moreover, self-employed people may work longer per week than employed workers. Another hypothesis is a low access to the preventive and therapeutic medicine. Craftsmen are not followed up by an occupational health system. There are few prevention and no systematic medical examinations by an occupational physician. Moreover, they may rarely be on a sick-leave (this is the reason of a potential healthy worker effect in this study). Craftsmen often work more than $8 \mathrm{~h}$ per day. They may not have enough time to consult a doctor. Overall, self-employed people (such as craftsmen or medical doctors) are often less medically followed-up.

Few studies have addressed craftsmen, especially in the context of occupational health. This study comparing craftsmen and employees from the same profession is the first of its kind, to our knowledge. Despite its numerous limitations, it provides some evidence showing that craftsmen are less healthy than employees. Further studies must be conducted to explore the different factors which could explain such a difference in health.

These factors include the differences in tasks, occupational exposures and prevention policies, but some other factors as well. Craftsmen do not benefit from a prevention 
and information system focused on occupational health. They cannot attend to problems by themselves because of the lack of time, funding, and knowledge. They might have some differences concerning the medical care. It is likely that craftsmen have resorted to the assistance of the health system less often (sick-leave, medical examination) than employees.

Further specifically designed studies have to be carried out. This is essential to understand better why craftsmen are less healthy than employees, and, what is most important, to propose some efficient solutions to this problem. Consequently, craftsmen's insurance fund ought to conduct similar medical examinations, and to promote safety rules, to better protect craftsmen's health.

\section{REFERENCES}

1. Chen J-D, Cheng T-J, Lin Y-C, Hsiao S-T. Job categories and acute ischemic heart disease: A hospital-based, case-control study in Taiwan. Am J Ind Med. 2007;50(6):409-14, http:// dx.doi.org/10.1002/ajim.20462.

2. Fujino Y, Iso H, Tamakoshi A, Inaba Y, Koizumi A, Kubo T, et al. A prospective cohort study of employment status and mortality from circulatory disorders among Japanese workers. J Occup Health. 2005;47(6):510-7.

3. Muntaner C, Hadden WC, Kravets N. Social class, race/ethnicity and all-cause mortality in the US: longitudinal results from the 1986-1994 National Health Interview Survey. Eur J Epidemiol. 2004;19(8):777-84, http://dx.doi.org/10.1023/ B:EJEP.0000036569.39399.68.

4. Bréchon F, Czernichow P, Leroy M, Blum-Boisgard C. Chronic diseases in self-employed French workers. J Occup Environ Med. 2005;47(9):909-15, http://dx.doi.org/10.1097/01. jom.0000169566.45853.79.

5. Laraqui CH, Caubet A, Harourate K, Belamallem I, Laraqui O, Verger C. [Occupational hazards in the Moroccan craft sector and proposal for occupational health services]. Sante Publiq. 1999;11(3):317-27. French.
6. Lesage F-X, Deschamps F. [Craftsmen and trades people health assessment]. Arch Mal Prof Environ. 2005;66(5): 456-464, http://dx.doi.org/10.1016/S1775-8785(05)79125-6. French.

7. Nylander LA, Dement JM. Carcinogenic effects of wood dust: review and discussion. Am J Ind Med. 1993;24(5): 619-47, http://dx.doi.org/10.1002/ajim.4700240511.

8. Carton M, Goldberg M, Luce D. [Occupational exposure to wood dust. Health effects and exposure limit values]. Rev Epidemiol Sante Publiq. 2002;50(2):159-78. French.

9. McBride D, Williams S. Audiometric notch as a sign of noise induced hearing loss. Occup Environ Med. 2001;58(1): 46-51, http://dx.doi.org/10.1136/oem.58.1.46.

10. Järvholm B, From C, Lewold S, Malchau H, Vingård E. Incidence of surgically treated osteoarthritis in the hip and knee in male construction workers. Occup Environ Med. 2008;65(4):275-8, http://dx.doi.org/10.1136/oem.2007. 033365 .

11. Engdahl B, Tambs K. Occupation and the risk of hearing impairment-results from the Nord-Trøndelag study on hearing loss. Scand J Work Environ Health. 2010;36(3):250-7, http:// dx.doi.org/10.5271/sjweh.2887.

12. Mirabelli MC, Zock J-P, Plana E, Benke G, Kromhout H, Norbäck D, et al. Employment status and use of respiratory protection among metalworkers, solderers and welders. Occup Environ Med. 2007;64(8):548-52, http://dx.doi. org/10.1136/oem.2006.031195.

13. Borm PJA, Jetten M, Hidayat S, van de Burgh N, Leunissen P, Kant I, et al. Respiratory symptoms, lung function, and nasal cellularity in Indonesian wood workers: A doseresponse analysis. Occup Environ Med. 2002;59(5):338-44, http://dx.doi.org/10.1136/oem.59.5.338.

14. Bohadana AB, Massin N, Wild P, Toamain JP, Engel S, Goutet P. Symptoms, airway responsiveness, and exposure to dust in beech and oak wood workers. Occup Environ Med. 2000; 57(4):268-73, http://dx.doi.org/10.1136/oem.57.4.268.

15. Baran S, Swietlik K, Teul I. Lung function: Occupational exposure to wood dust. Eur J Med Res. 2009;14 Suppl 4:14-7. 
16. Jacobsen G, Schaumburg I, Sigsgaard T, Schlunssen V. Nonmalignant respiratory diseases and occupational exposure to wood dust. Part I. Fresh wood and mixed wood industry. Ann Agric Environ Med. 2010;17(1):15-28.
17. Jacobsen G, Schaumburg I, Sigsgaard T, Schlunssen V. Nonmalignant respiratory diseases and occupational exposure to wood dust. Part II. Dry wood industry. Ann Agric Environ Med. 2010;17(1):29-44.

This work is available in Open Access model and licensed under a Creative Commons Attribution-NonCommercial 3.0 Poland License - http://creativecommons.org/ licenses/by-nc/3.0/pl/deed.en. 